\title{
EL LLAMADO DE LA LLUVIA: LA TARQUEADA EN ARICA COMO EXPERIENCIA Y PERFORMANCE SONORA
}

\author{
THE CALL OF THE RAIN: TARQUEADA IN ARICA AS SOUND \\ EXPERIENCE AND PERFORMANCE
}

Andrea Chamorro PÉrez ${ }^{A}$

En el entendido de que el cuerpo es la base de la percepción, exploro las experiencias y performances sonoras de los/as bailarines/as de tarqueadas en el escenario del Carnaval Andino "Inti Ch'amampi, Con la Fuerza del Sol", que se celebra en Arica (Chile) desde el año 2002. Reviso, específicamente, los significados culturales del sonido de las tarkas en el marco del calendario agrofestivo andino y de la historia de creación de los grupos de tarqueadas en la ciudad. Asimismo, abordo la dimensión sonora de las experiencias dancísticas como un diálogo a través del cual los/as bailarines/as aymaras urbanos establecen relaciones sensibles, emocionales y memorísticas con la comunidad festiva.

Palabras clave: Carnaval andino, Tarqueada, Experiencia sonora, Performance, Arica.

Assuming the body as the basis of perception, in this paper we explore the sound experiences and performances of tarqueada dancers in the "Inti Chamampi, with the Force of the Sun" Andean Carnival, organized in Arica (Chile) since 2002. We specifically examine the cultural meanings of the sound of the tarkas within the framework of the agro-festive Andean calendar, as well as the history of the creation of tarqueada groups in the city. We also explore the sound dimension of the performative experiences as a dialogue through which urban Aymara dancers establish emotional, affective, and memory relationships with the festive community.

Keywords: Andean carnival, Tarqueada, Sound experience, Performance, Arica.

\section{INTRODUCCIÓN'}

El Carnaval Andino "Inti Ch’amampi, Con la Fuerza del Sol" se celebra en Arica, Chile, desde el año 2002 gracias al trabajo de legitimación y negociación que las agrupaciones folclóricas aymaras han mantenido en torno al uso del espacio público de la ciudad (Chamorro 2013), y también, pese a las disputas en torno a la soberanía territorial, resultado de la Guerra del Pacífico (1879-1883) y a los procesos de discriminación y estigmatización de las poblaciones indígenas y extranjeras que le siguieron (Gundermann et al. 2014). ${ }^{2}$ Esta festividad ha motivado la adherencia y participación de miles de bailarines/as, músicos y espectadores/as indígenas, afroariqueños y no-indígenas de Chile, Perú y Bolivia, promoviendo la circulación transfronteriza de prácticas y recursos festivos de las comunidades rurales y del acervo folclórico andinourbano de Bolivia (trajes, pasos de bailes, instrumentos musicales, contrato de músicos, bloques de bailarines/ as, entre otros). El Carnaval Andino destaca por su carácter competitivo y porque su performance dibuja cíclicamente los contornos de una comunidad festiva (fig. 1). Se realiza aproximadamente dos semanas antes de los carnavales de los pueblos de la cordillera andina.

\footnotetext{
A Andrea Chamorro, Departamento de Antropología, Universidad de Tarapacá. Arica, Chile. ORCID: 0000-0003-2552-1681. E-mail: achamorro@uta.cl
} 


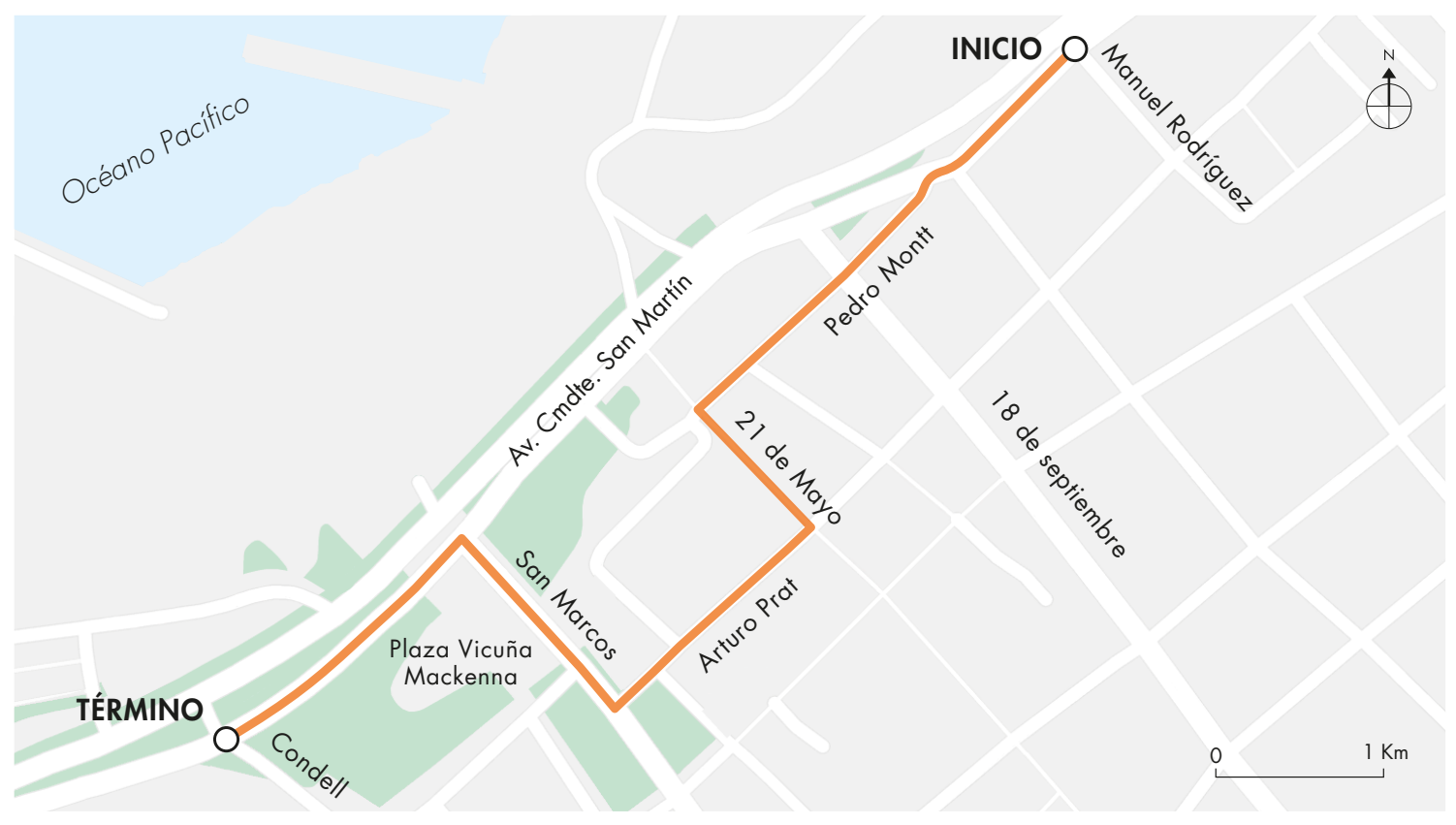

Figura 1. El circuito o "Entrada del Carnaval" recorre las principales calles del centro histórico de Arica. Figure 1. The circuit or "Entrance of the Carnival" parades the main streets of the historic center of Arica.

En este escenario, comprender las danzas del Carnaval como performance me permitió asirlas como una experiencia existencial, simbólica y sensorialmente densa, donde los lenguajes kinésicos, visuales y sonoros devienen en medios de comunicación de valores y significados culturales (Cánepa 2008), y a la vez, son corporizados por los/as actuantes desde un intenso estado interior que favorece la interacción emocional con el mundo (Csordas 1990, Surrallés 2009). Estos aspectos me llevaron a cuestionar mi lugar como observadora y participante (bailarina de tarqueada), desde donde objetivar ese "sentimiento" o "emoción" que los/as bailarines/as aymaras decían llevar en la "sangre" o que "corría por sus venas", pues no solo resultaba sumamente difícil traducir mi propia experiencia somática en palabras, sino que los mismos/ as bailarines/as se frustraban en el intento de describir verbalmente sus experiencias kinestésicas, perceptivas y emotivas. Sin embargo, constaté que las entrevistas no estructuradas constituían "diálogos corporizados", ya que los discursos se vivían performáticamente como una práctica interpretativa de una experiencia compartida (Denzin 2001), por lo que fue principalmente en la interacción y conversación con bailarines/as y ñustas de tarqueadas, el lugar desde el cual me aproximé significativamente a la singularidad y características de su sensibilidad. ${ }^{3}$

Complementariamente, analicé todas las descripciones, categorizaciones e interpretaciones que referían tanto al sonido y sus propiedades, como a la capacidad de escuchar. Desde este universo de sentido fueron revelándose las experiencias y performances sonoras de los/as bailarines/as de tarqueadas, como ámbitos de la subjetividad e interacción corporizada con el ambiente festivo.

Considerando que el cuerpo es la base de la percepción (Csordas 1990, Classen 1997, MerleauPonty 2008, Surrallés 2009), Constance Classen (1997) sostiene que los sentidos (vista, oído, tacto, gusto y olfato) también permiten transmitir significados culturales y, en el caso de los Andes, existiría un "modelo sensorial" que privilegia el sonido y la vista como vehículos que organizan la interacción con el mundo. De este modo, Classen (1990: 723) destaca que para la cosmovisión andina "the sound is the primary medium of creation: the world is called into being and animated by the voice of Viracocha, the creator". Estos aspectos se relacionan con la facultad de hablar y escuchar las voces que vienen desde lo sagrado, así como a la idea de que el discurso y la audición serían estrategias de 
apelación a un principio de reciprocidad con la divinidad (Classen 1993). Noción de diálogo que, como planteo más adelante con respecto al "escuchar", los/ as bailarines/as aymaras asocian tanto a la percepción sonora de la "energía” y "alegría" del público (gritos, aplausos, vitoreo) como a la posibilidad de comunicarse acústica, visual y táctilmente con el mismo a través de sus performances (cantos, sonido de pasos y trajes, gritos-consignas).

Aunque la preponderancia del núcleo sonoro en este paradigma refiere a que "sound and hearing are thought to be of more use in uniting people, land, and gods and in animating the cosmos" (Classen 1990: 731), importa destacar que dado el carácter multisensorial de las prácticas rituales andinas (sonido/música, visión/ vestido, movimiento/danza, gusto/comida-bebida, olfato/incienso), resulta difícil separar sus funciones o determinar sus grados de importancia. Motivo por el cual existirían una serie de analogías o experiencias sinestésicas que producen acoplamientos sensoriales, de modo que "visual experiences are linked to auditory, tactile and even olfactory experiences to create stereotypes and emblems that provide models for the individual's journey" (Isbell 1985: 305 en Classen 1990).

Al respecto, Rosalía Martínez (2014) señala que la música se encuentra conectada a colores y movimientos, de modo que la performance musical puede oírse, verse y sentirse. Observando que los instrumentos musicales se ejecutan caminando o bailando, es posible identificar piezas musicales que marcan los desplazamientos de un lugar a otro (pasacalle o llampuruy, traducido del quechua como "ir camino"). A su vez, estos movimientos producirían distintas percepciones sonoras, es decir, una cinética ligada al desplazamiento "de sonidos que se alejan, se acercan, se desplazan en una dirección o en otra" (Martínez 2014: 94). Asimismo, Zoila Mendoza (2010) observa que en la peregrinación al santuario del Señor de Qoyllurit'i (Cusco, Perú), el modelo sonoro-visual propuesto por Constance Classen se actualiza en un esquema donde cobra protagonismo lo visual y auditivo de la experiencia, pero pone énfasis en el sentido de la sinestesia o sensación del movimiento que se acopla a una melodía que describe como hipnótica, pues induciría a un estado de ensimismamiento o meditación durante el cual los/as peregrinos/as no solo expiarían sus culpas y pecados, sino que agudizarían sus sentidos y la percepción de sí mismos. En sus palabras:
La idea de que el corazón, o ellos mismos, revive/n cuando caminan con la música fue expresada de diferentes formas y utilizando diferentes verbos asociados con la renovación de la vida y la vitalidad. El presidente de la comparsa, por ejemplo, indicó: "Musicata tokaqa uyarispa noqaykupas sonqoylu llanllarin" ("Al oír tocar la música nuestros corazones se avivan/reverdecen"). Otro miembro dijo que con la música su "corazón florece” ("sonqoy phancharin”). En las conversaciones, la alusión a estos sentimientos de renovación y vitalidad iba casi siempre asociada con comentarios sobre la "alegría" que se genera en la combinación de caminar a pie y la música del chakiri (Mendoza 2010: 32-33).

En suma, sugiero que, entender el sonido como eje del "modelo sensorial andino", permite reconocer el carácter organizador del campo auditivo respecto de una relación sensorial y significativa con el mundo. Por lo que, si bien reconozco el protagonismo de la visión y la dimensión multisensorial de las prácticas rituales, el presente trabajo es una propuesta de exploración que pone acento en las experiencias sonoras de los/as bailarines/as de tarqueadas en Arica, como registros que permiten aproximarse al significado de las emociones vividas y a la particularidad de sus performances. En esta perspectiva, me referiré a la estética sonora de las tarqueadas como dominio constitutivo de la celebración de carnavales y, fundamentalmente, a las características del diálogo sonoro que los/as bailarines/as establecen con la comunidad festiva. Finalmente, aludiré a la noción de "escuchar" como un estado interior que, asociado a la "sangre" y al "corazón", remite a las relaciones sensibles, emocionales y memorísticas que los/as bailarines/as establecen con la comunidad festiva.

\section{EL SONIDO EN/DE LOS CARNAVALES}

Entre las sociedades agroganaderas de los Andes, el transcurrir del tiempo representa una experiencia que es resultado de la observación de los acontecimientos climáticos y de los cultivos, donde "lo que separa y al mismo tiempo junta los acontecimientos son actividades agrofestivas y rituales que a la manera de nudos o eslabones marcan el fin y el inicio de los aconteceres" (Rengifo 2006: 27). Desde esta perspectiva, la música contribuye a definir, marcar e intensificar el tiempo ritual y la transición estacionaria, así se reconoce una época fría-seca asociada al sonido de zampoñas, quenas y sikus (IICEP 1973, Martínez 1996, Sigl 2012), y una época lluviosa-cálida que se extiende desde la Fiesta de 
Todos los Santos (mes de noviembre) hasta la despedida de los carnavales (entre enero y marzo) (Sigl 2009, 2011 y 2012), y que se vincula con lo femenino, la fertilidad, la abundancia de lluvias y el crecimiento de los sembríos, a través de la interpretación de "una variedad de flautas llamadas genéricamente pinkillu” (López 2007: 47).

La celebración de carnavales es fruto de la política colonial en los Andes y comparte con la tradición medieval europea rasgos como el culto agrario y de gentilidad, ideas cristianas de ayuno y Cuaresma, algunos elementos de inversión y paradoja, entre otros (Gaignebet 1984, Caro Baroja 1984, Prat i Carós 1993, Flores 2001, Bajtín 2003). Sin embargo, autores como Harris (1983), G. Martínez (1996), Gérard (2003) y Gavilán y Carrasco (2009) señalan que en los Andes el carnaval se asocia a la noción de Anata, palabra aymara que se traduce como "el tiempo de jugar" o "fiesta de los demonios", que se vincula a los encuentros y competencias al finalizar las lluvias, y a las labores de precosecha. La celebración de las primicias y la intención de propiciar la fertilidad de los productos venideros son sus significados más notables (Gérard 2003). Motivo por el cual diversas investigaciones han coincidido en representarla como un año nuevo o de renovación de la fertilidad cósmica, humana y no-humana (Harris 1983, G. Martínez 1996, R. Martínez 1996, Bigenho 1999, López 2007, Gavilán \& Carrasco 2009).

En el caso de Arica, el lento pero sostenido proceso de resignificación de los espacios urbanos por parte de la colectividad aymara migrante (década de 1960 y hasta la actualidad $)^{4}$ ha cristalizado en la construcción de un ciclo festivo que hace de lugares como el valle de Azapa y la ciudad de Arica (comuna homónima, Región de Arica y Parinacota, Chile) escenarios de celebraciones anuales andinas (Grebe 1986). De modo que Todos los Santos, Cruces de Mayo, Machaq Mara, martes de challa y Carnavales irrumpen en los espacios costeros resignificando y provocando una fragmentación en la trama de exclusiones interétnicas que impuso la "chilenización”. Si bien, el Carnaval Andino es concebido por sus artífices como una plataforma social y cultural que permite visibilizar a la ciudadanía indígena en clave de autorrepresentación (Chamorro 2017), su observación también me permitió comprender que se trata de un 'tiempo corporizado' por los/as bailarines/as. ${ }^{5}$ Por un lado, es un ámbito de la experiencia que se vive, en palabras de algunos interlocutores/as, como un "año nuevo" o "tiempo de alegría", pues abre la posibilidad de expresar, "liberar" o "sacar afuera" lo que guarda en el interior; por otro, se trata de un tiempo que provoca un "sentimiento" o "emoción" que en todos los casos parece aludir a una sensación entrañable, no transmisible verbalmente, pero que algunos bailarines/as ubicaban gestual y metafóricamente en el corazón.

En lo que respecta a estas expresiones sensibles, Gabriel Martínez (1996) sostiene que, entre los jalq’a (Bolivia), la música de carnaval es comprendida como "Saxra" (diablo o supay), porque "produce ese proceso espiritual de 'entregarse al Carnaval' y de pérdida del sí mismo en las personas. Por lo tanto, es la música también la que permite cumplir el propósito de significar el tiempo' como una vivencia interior" (G. Martínez 1996: 307). Asimismo, Rosalía Martínez añade que, a diferencia de otras músicas, la de carnaval intensifica las emociones, de modo que "hace llorar,' 'roba el corazón', como el sajra, la música 'tienta', es decir se produce un estado de pérdida de los sentidos" (R. Martínez 1996: 315). No obstante, entre los/as bailarines/as de Arica, la saturación sonora de la fiesta y la sensación de tocar y ser tocado por la atmósfera festiva inducen a la expresión de un complejo de emociones que se definen unívocamente como "alegría" o "emoción". También advierto que las cualidades sonoras de las tropas o conjuntos de tarkas que los/as acompañan -en términos de "vibración", "fuerza" y "bulla" - remiten a una época de encuentro y de performance de origen rural. Por tanto, la escucha no se asocia tanto a una función del oído, sino más bien a la dimensión sensible de una subjetividad corporizada que mantiene un diálogo con el ambiente y con una noción del sí mismo vinculado al recuerdo y celebración de la procedencia.

\section{LAS TARQUEADAS EN ARICA}

La 'tarqueada' es un género musical y coreográfico que celebra la floración y fertilidad del período estival. Su nombre deriva de las flautas de pico de origen colonial denominadas tarkas o tarqas (Copa 2010). ${ }^{6}$ De acuerdo con Rossells et al. (2009), es un instrumento "que recibe las melodías de la naturaleza, para pedir clemencia frente a las sequías, los excesos de lluvia o cualquier otro fenómeno climático que afecte los sembradíos" (Rossells et al. 2009: 350). En este sentido, y aunque su timbre dulce y femenino "es adecuado para expresar sentimientos de alegría y júbilo propios del Carnaval" 
(IICEP 1973: 4), sus melodías son prohibidas una vez concluidos los carnavales, pues despertarían el poder de los ancestros. ${ }^{7}$

Si bien no hay claridad sobre el origen exacto de la tarka, habría consenso en que posee una amplia presencia en los alrededores del Titicaca (Borras 2011), y que se habría difundido hacia regiones como Puno, Noroeste Argentino y norte de Chile (Díaz \& Mondaca 2000, Copa 2010, Borras 2011). Por lo cual, su modelo organológico se habría transformado notoriamente, pues no solo emergen nuevas formas de ejecución, sino que la misma "oferta en términos de tropas y de organizaciones armónicas internas tiene poco que ver con lo que existía antes" (Borras 2011: 64).

En el caso de la Región de Arica y Parinacota (Chile), Díaz y Mondaca (2000) proponen que la presencia y preponderancia de la tarka se debe a dos procesos de inmigración de población aymara boliviana en Chile, una hacia la cordillera y precordillera a principios del siglo xx (o migración escalonada) y la otra hacia las ciudades y valles costeros en la década de 1960 (o migración directa) (Grebe 1986). En el caso de las tierras altas de Arica, su emergencia se debería al contrato de obreros aymara-bolivianos en la explotación azufrera de Tacora, Villa Industrial y Tarapacá, y en el mineral de Choquelimpie (Díaz \& Mondaca 2000); quienes "no tardaron en establecer vínculos de parentesco con la población local, principalmente en la zona de Putre y Socoroma" (Díaz \& Mondaca 2000: 68), o ser contratados como músicos de los carnavales.

Consecuentemente, en el Carnaval de Arica se reconocen dos tradiciones de tarqueadas: una proveniente de la cordillera chilena, que se relaciona directamente con los carnavales de los pueblos rurales, y otra con los "valles costeros" (valles de Azapa y de Lluta), pero que corresponden a expresiones de las poblaciones aymaras migrantes de los Departamentos de La Paz y Oruro (Bolivia) que se instalaron como agricultores y asalariados agrícolas en los valles desde mediados del siglo xx. Como resultado, en la década de 1970

\footnotetext{
Ya había tres agrupaciones [de tarqueadas], también salió San Pedro de Totora porque se juntaron de a grupo, por ejemplo yo soy de San Pedro de Totora, entonces esta gente... ya juntémonos, somos de esta agrupación, los que somos del pueblo de Sajama hagamos esta agrupación y así, a pesar de que esos pueblos estaban en Bolivia, se identificaban acá y mostraron sus tradiciones, sus costumbres (Entrevista con bailarín y dirigente, Hijos de Saxamar y Morenada San Pedro de Totora).
}

Siguiendo a Luis Copa (2010), importa notar que las tarqueadas provenientes del norte del Departamento de Oruro y del sur del Departamento de La Paz, corresponderían al "estilo Curahuara" o "tarqueada aymara", el cual abarca parte de las Yungas, los contornos del lago Titicaca y el norte de Oruro. En el caso de Arica, tanto los patrones migratorios de la población aymara boliviana antes mencionados como las relaciones sociales y culturales transcordilleranas, que el altiplano y la costa han mantenido por extensos períodos de tiempo (Gisbert 1999, Díaz \& Mondaca 2000, Copa 2010), sugieren profundizar en la posible difusión de este estilo y sus transformaciones organológicas y rítmicas (fig. 2).

En todos los casos, las tarkas pueden ser ejecutadas en grupos llamados tarqueadas, tríos o de forma individual, como lo hacen los pastores de montaña (Romero 2012). Quienes participan en grupo "desarrollan una actividad de trabajo con las tarqas, las kajas y el batir de las wiphalas [o banderas], pero al mismo tiempo, con un movimiento cadencioso y armónico todos bailan al son del compás" (López 2007: 96). Las canciones de las danzas comunitarias, denominadas wayñu, se complementan con coreografías que reúnen a parejas de hombres y mujeres (o solo mujeres) en filas que trazan líneas, círculos y espirales mientras se desplazan por pueblos y calles llevando "alegría, diversión y juegos, como manifestación de la celebración del inicio de la época de cosecha y las expectativas de una buena producción" (Rossells et al. 2009: 349). En este sentido, es destacable que las tarqueadas del Carnaval de Arica, aunque corresponden a agrupaciones culturales $\mathrm{o}$ asociaciones indígenas urbanas, mantengan la concordancia con la clausura ritual de la época lluviosa en la cordillera, y que la mayoría de los grupos inicien sus procesos de ensayos musicales y dancísticos a mediados del mes de noviembre y se disuelvan una vez concluidas las celebraciones de carnavales. Cabe señalar, además, que las relaciones entre sus miembros (bailarines/as y músicos) se caracterizan por conservar los nombres de sus lugares de origen, y su membresía se sostiene tanto en la reproducción y creación de lazos parentales como en una tenaz participación festiva en los ciclos festivos rurales y urbanos.

En la actualidad, el Carnaval de Arica cuenta con alrededor de seis agrupaciones aymaras de origen boliviano, en orden de la antigüedad dadas sus fechas de fundación: Chapicollo y Llicapani (1967), Villarroel "A" (1968), Villarroel “B” (1968), Monterani (1990), Curahuara 


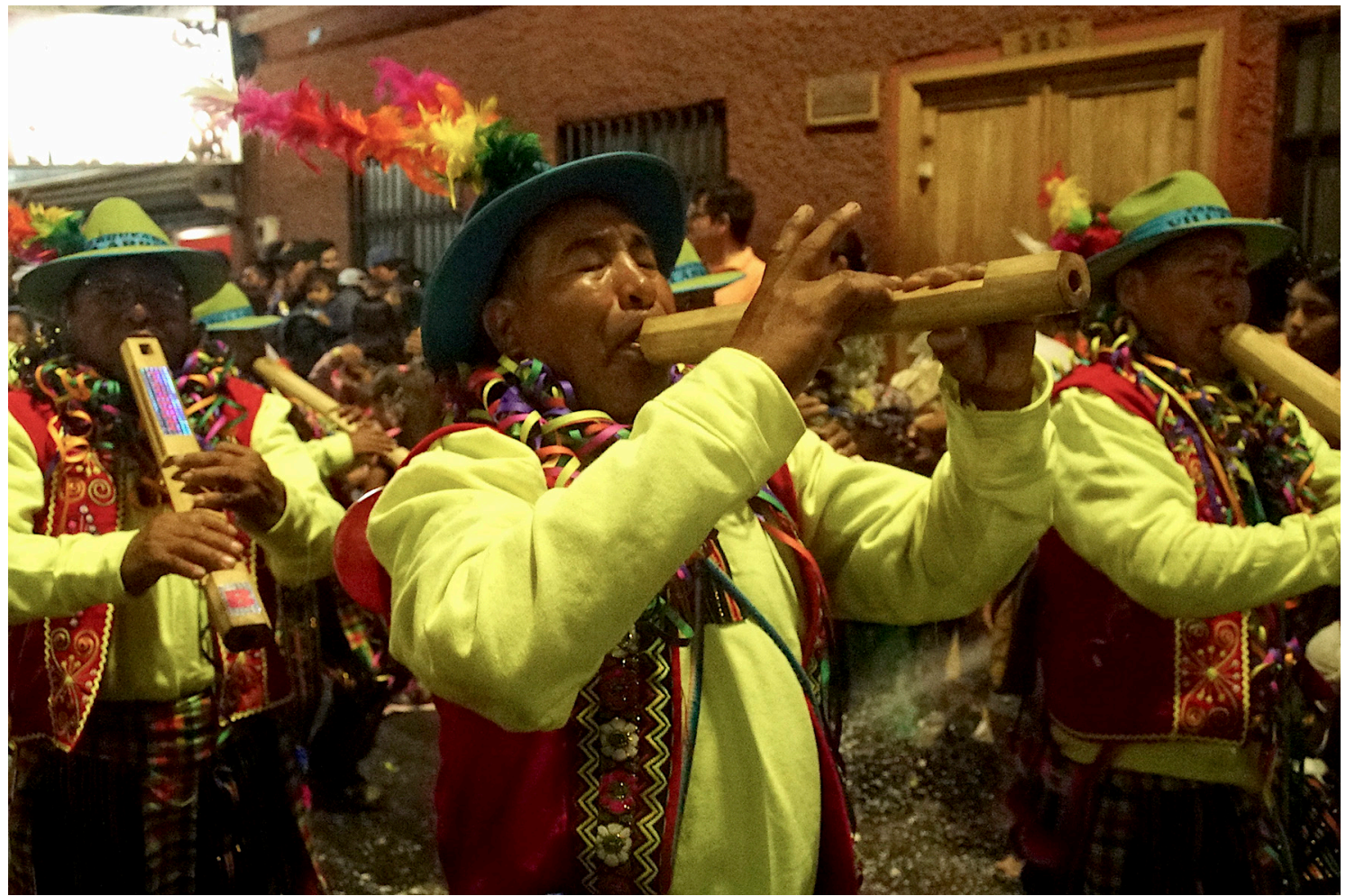

Figura 2. Tarqueada Villarroel B subiendo por calle Arturo Prat, Carnaval Andino año 2018. (Fotografía: J. P. Donoso). Figure 2. Villarroel B tarqueada going up Arturo Prat Street, Andean Carnival 2018. (Photograph: Juan P. Donoso, 2018).

de Carangas (2004) y San Pedro de Totora (2014). Existe un total de once agrupaciones de los pueblos aymaras chilenos, autodenominadas "Hijos", entre las que se cuentan: Hijos de Guallatire (1995), Hijos de Caquena (1999), Chapiquiña, Pachama y Copaquilla (1999), Hijos de Saxamar (2000), Molino (2001), Anata Thuquri de Putre (2005), Volcán de Guallatire (2005), Socoroma (2008), Jallalla Parinacota (2011), Hijos de la Comuna de General Lagos (2012), Hijos de Parinacota (2013).

Cada agrupación cuenta con sus propios "tocadores", -forma en que los/as bailarines/as definen a los intérpretes de tarkas-. Sin embargo, hay casos en que las tarqueadas no cuentan con músicos o bien estos son muy ancianos, por lo que frente a la dificultad de generar recambio generacional y a las exigencias del formato competitivo del Carnaval, deben gestionar y pagar un contrato de músicos que suele incluir su participación en algunos ensayos, el Convite y los tres días de la Entrada del Carnaval. ${ }^{8}$ En algunos casos, esta situación se interpreta como una crisis de las tradiciones, puesto que no habría espacios de transmisión de saberes musicales, ni jóvenes de las comunidades interesados en aprender la ritualidad y estética sonora de las tarkas. ${ }^{9}$ No obstante, importa notar que los/as bailarines/as tienden a exigir la conservación de determinados ritmos y estilos asociados a sus pueblos, a la vez que se interesan por innovar en sus repertorios creando nuevas y originales canciones. Cito como ejemplo la letra de una canción de la "Tarqueada Virrarroel A", que se presentó en el Carnaval del año 2015, pues resulta explícita la identificación de los carnavales urbanos con un tiempo de encuentro, seducción y contacto amoroso (Vokral 1996):

\footnotetext{
Bajo la lluvia hemos llegado tomando cervecita Cristal en los carnavales.

La chica que me está mirando desde el pueblo donde nací amorcito viva Villarroel A.
}

Junto con las tensiones que provoca la oscilación entre tradición e innovación, importa notar además que en 


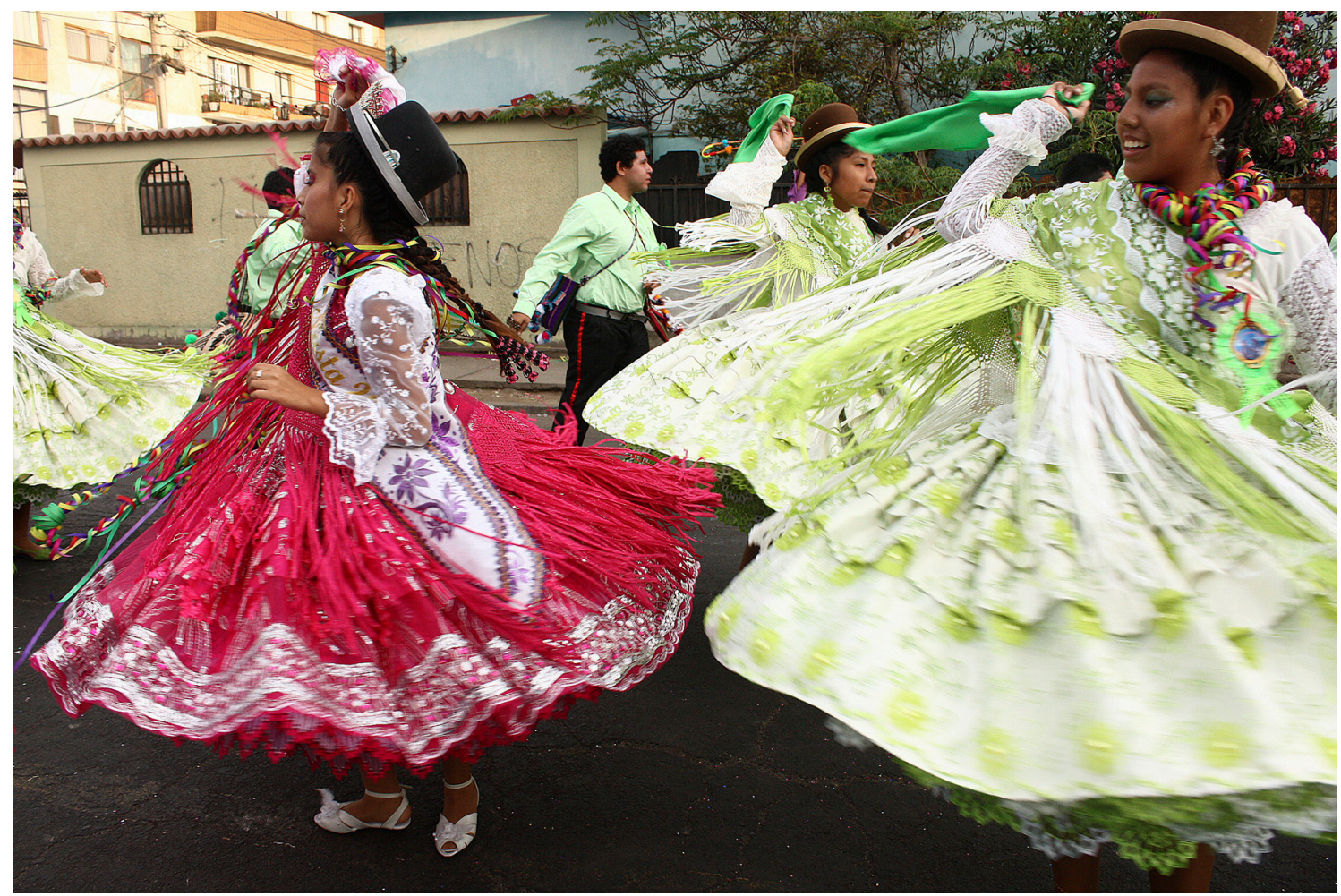

Figura 3. Anata Thuquri de Putre sobre calle Arturo Prat, Carnaval año 2014. (Fotografía: A. Chamorro). Figure 3. Putre's Anata Thuquri on Arturo Prat Street, Carnival 2014. (Photograph: A. Chamorro, 2014).

las performances de las tarqueadas se manifiestan las complejas relaciones nacionalistas entre colectividades aymaras (Díaz \& Mondaca 2000). Por ello, los grupos se esmeran en mantener estilos propios, que se reflejan en trajes, canciones, coreografías e incluso en los tipos de instrumentos empleados (tamaños, número de tocadores, tipos de bombo, presencia de caja y platillos, entre otros); así como también presentan variaciones importantes en la ejecución musical. Por ejemplo, -según palabras de un bailarín de Caquena- los wayñu de las tarqueadas de los pueblos chilenos resultan notoriamente más rápidos que los ejecutados por los valles costeros. Estos últimos presentan bailes con giros y pasos más veloces y dinámicos, al punto que se les denomina "rock and roll"; sin embargo, en la terminación de las canciones, cuando el conjunto de tarkas toca una nota final larga antes de reiniciar (Stobart 2011), el sonido "tara" o zumbido rico en armónicos resultantes, es notoriamente más dilatado que en los pueblos chilenos, por lo que el descanso o la pausa antes del cambio de un paso de danza a otro, es más prolongado. ${ }^{10}$
Pese a estas diferencias, cada tarqueada concibe que sus performances conforman una auténtica representación de la "emoción" y "alegría" de los carnavales, y una experiencia colectiva que es promovida y vivida intensamente por cada uno de los actuantes durante los tres días de Carnaval. En este sentido, sugiero que la exploración del vínculo corporal, estético y emocional aproxima a la sensibilidad de los/as bailarines de tarqueadas, y con ello a una definición corporizada de sí mismos/as que emerge de la interacción festiva. Particularmente, y en el entendido de que en los Andes el sonido refiere a una noción de diálogo sensible entre las personas y el mundo que se produce a través de contactos acústicos diversos (Stobart 2006), comprendo el universo multisensorial del Carnaval como movimiento que conjuga música, bailes y gente, en el que intervienen tanto quienes producen sonidos como aquellos que los oyen (Bigenho 1999). Experiencia y performance sonoras en las que nociones corporales como "sangre" y "corazón" adquieren connotaciones propias (fig. 3). 


\section{Un diálogo sonoro}

El Carnaval de Arica ha cumplido un rol preponderante en la resignificación social y simbólica del espacio público. Por una parte, la música andina se ha legitimado como expresión artística, pasando de un acto privado -secreto o semiclandestino a lo largo de la década de 1970- a convertirse en un bien de prestigio social y simbólico entre las agrupaciones de bailes. Y por otra, la fiesta produce un ambiente sonoro donde intervienen cientos de músicos, miles de bailarines/ as, espectadores y actores diversos, configurando -en palabras de Bigenho (1999)- una suerte de "soberanía sonora", cuya singularidad consiste en que a la vez que fija estas estéticas en las subjetividades de los actuantes y escuchas, se diluye con el término de la fiesta.

Con respecto a los criterios de competencia del Carnaval, se valora positivamente la interacción con el público, al punto de que los/as bailarines/as consideran como prioritario ganar la atención de los espectadores. Sin embargo, también comprenden que es la capacidad de escuchar y ser escuchados lo que permite diferenciarlos del desempeño de otros grupos, por lo que se establece un diálogo y vínculo sonoro que posee propiedades táctiles y emocionales. Así, por ejemplo, el empleo de la voz, se considera medular para el objetivo de "animarse" y "animar" a los/as espectadores/as, pues la expresión verbal a través de canciones y gritos de entusiasmo constituyen performances sonoras que refuerzan la alegría y vigor de los carnavales, a la vez que transfieren esos sentimientos al público. De este modo, junto a la idea de que canciones y consignas han contribuido a forjar una suerte de sello o estilo en algunas tarqueadas. Es fundamental comprender que la intensidad de sus voces, y por tanto la "energía" del grupo, es el eje sobre el cual descansa el objetivo de conseguir la adherencia sensorial y emocional de la audiencia.

Fuimos [...] nos connotamos con los trajes, trajes de primera salida, los pepinos trajeron harta gente y el cariño de la gente es lo que más nosotros recibimos como un regalo, porque la gente todos gritan el grito que tenemos y todos [...] ese día que me vine del Carnaval, todos estaban gritando: “Pónele color, pónele color!", ese es como el grito típico de nosotros, porque después de eso todos nos copiaron con el grito [...] “¡Pónele color!”, el “ised, sed!” [...] entonces como que la gente quedó grabada, po, y sabe que Villarroel B es [...] de ese grito, la gente nos aplaude, nos sigue [...] (Entrevista con bailarina y ñusta, Tarqueada Villarroel B).
Los aplausos, gritos y expresiones de asombro y alegría de los espectadores significan, para los bailarines/as, una demostración del efecto positivo de sus actuaciones sonoras. Y unido a la satisfacción de recibir y sentir esta respuesta, perciben que en el intercambio sonoro unos y otros resultan transformados por la alegría del carnaval.

\footnotetext{
Tengo que salir y veo realmente a todos $[\ldots]$ cómo lo están haciendo, cómo se gritan entre ellos “iya, vamos con todo!" Y escuchar eso y ver eso igual [...] igual a una la emociona, este bloque. Realmente somos una familia, es muy bonito, después al final quedar ahí [...] a los pies del morro, todos sentados y conversar [...] y decir sí [...] gritamos, lo dimos todo y la gente nos aplaudió y nos fue bien, o tal vez en un momento nos equivocamos, teníamos que haber hecho ese paso, es muy bonito, sí. Se siente muy bien estar al medio de tanta alegría más que nada, mucha alegría (Entrevista con bailarina y ñusta, Tarqueada Villarroel A).
}

En lo que respecta a la música, el aprecio por la alta magnitud del sonido está asociada a la dificultad de escuchar el ritmo en el contexto de la saturación acústica de la fiesta y de los desplazamientos coreográficos a lo largo de las calles. Sin embargo, también se relaciona con la noción, en términos performáticos, de que la intensidad del sonido tiene el efecto de imprimir "fuerza". De ahí que sea especialmente valorado el acompañarse de tarqueros que interpreten -toquen y soplen- con vigor, aunque no necesariamente sepan digitar el aerófono. Aspecto que, de acuerdo con la explicación que nos proporciona un músico autodidacta y multi-instrumentista, parece corresponder a una estética sonora que no parece vincularse a un tipo particular de instrumento musical.

\footnotetext{
En una festividad, en unas localidades van las bandas, van las orquestas y de repente yo estoy tocando zampoña y la zampoña suena mucho menos que una banda, pero entramos a la iglesia, cuando hacen un saludo a la Virgen, entramos a la iglesia y entramos los dos metiendo bulla, aunque así suene el otro, yo tengo que sonar igual. Entonces [...] en cuanto a eso no es preocupante, porque uno tiene que sonar igual y tiene que tocar igual (Entrevista con músico, Tarqueada Jallalla Parinacota).
}

Por otra parte, considerando que la colectividad aymara urbana mantiene relaciones familiares y económicas translocales con la precordillera-altiplano (ciudad-campo), y que los residentes de los valles surten de productos agrícolas a la región y al país (González 1995), es posible sostener que las tarqueadas, en contextos desérticos como Arica y los valles costeros, no ha perdido su vínculo con la estación lluviosa ni con las labores agrícolas; en con- 
secuencia los ensayos comienzan tras la celebración de la Fiesta de Todos los Santos, prevaleciendo la intención de transformar el paisaje de la cordillera a través del sonido. En el caso de las tarqueadas del valle de Azapa, por ejemplo, buscan y necesitan ser escuchados e incidir en la productividad de la tierra, pues de ello depende su sustento. En palabras de un taxista, agricultor y bailarín del valle de Azapa,

Se dice que si no hacemos zumbar bien los bombos [...] y no tocamos bien la música [...] no llueve en la cordillera, no llueve entonces [...] en estos carnavales, en enero hay que tocar con harto ritmo, con harta fuerza y con harta fe lo que es la tarka y lo que es el bombo, porque eso quiere [...] la madre tierra, po, la Pachamama como la llaman, eso quiere el universo, música, bulla según los ancestros y de ahí ya nos responde la Pachamama [...] si no le da diversidad [...] a la cordillera, al universo no nos responden, porque toda la parte cordillerana viven de esa agua, nosotros como somos del valle también, po, mientras haiga bajada del río pucha $[\ldots]$ tenemos regadío en abundancia, po, $[\ldots]$ pero mientras no haiga agua $[\ldots]$ vamos a hacer zumbar los bombos, los tambores, la música que nos pide la Pachamama (Entrevista con bailarín y dirigente, Tarqueada Villarroel A).

En este marco, es significativo considerar que la música andina ocupa un lugar central en el universo sonoro de los residentes andinos en Arica, y que se actualiza a la manera de un habitus, pues se trata de un gusto y sensibilidad que dispone a su apreciación y reproducción aun cuando se conflictúe con la imposición de nuevas disposiciones corporales (Bourdieu 1999). Sin embargo, en el contexto histórico de las relaciones interétnicas en Arica, su preponderancia radica en la vitalidad y persistencia de los espacios de socialización familiar y comunitaria, así como a la agencia en la creación de organizaciones deportivas y culturales urbanas, como es el caso de las tarqueadas (Zapata 2001).

Cabe recordar que, en la década de 1970 la música andina fue proscrita y considerada subversiva por la dictadura militar chilena, y las poblaciones aymaras mismas fueron estigmatizadas y discriminadas como “indias" y extranjeras (González 1997, Gundermann et al. 2014). Si bien este escenario ha cambiado lentamente, en Arica la colectividad aymara ha logrado crear diversos espacios de socialización de sus universos musicales. Por ejemplo, resulta sugestivo mencionar que los/as bailarines/as, así como devienen en fieles oyentes de los programas radiales locales que promueven las actividades de las distintas agrupaciones (p.e. programa Waliki, Radio Andina), también participan de circuitos locales de difusión de cumbia electrónica, sayas, caporales y tonadas románticas que se desarrollan en centros de eventos temáticos de la ciudad. En este universo urbano de sensibilidades, gustos y prácticas corporales, la preferencia, apreciación estética y performance de las tarqueadas destacan como formas de transmisión de memorias corporizadas (Taylor 2015), a través de las cuales los/as bailarines/as actualizan y comunican el recuerdo de los abuelos, el origen rural, y viven su "llamado" como un "sentimiento".

Mi agüelo parece que es, por parte más atrás boliviano, por parte de mi agüela peruana, pero mi agüelo gusta del [...] tarka, porque desde niño siempre ha escuchado tarka en su casa, eso fue por un lado lo que me fue llamando. Y de todos sus nietos [...] yo sé que está [...] ahora no lo he visto hace tiempo, pero él está súper orgulloso, súper orgulloso de que una nieta de todos, esté bailando en el Carnaval y más encima tarqueada (Entrevista con bailarina y ñusta, Tarqueada Curahuara de Carangas).

\section{Escuchar con/la sangre}

Las melodías de las tarkas son corporizadas y experimentadas como una vivencia interior que favorece el despertar de percepciones y emociones específicas. Desde esta perspectiva, sugiero comprender la noción de escucha como una habilidad ligada a un imaginario corporal que concibe la "sangre" y el "corazón" como ejes de la percepción y de las cualidades sociales y morales de las personas (Polia 1989, Arnold 1994, La Riva 2005, Gavilán 2005). Por lo que, si bien el aprendizaje de los pasos y coreografías de tarqueadas se produce por imitación visual de pasos y posturas, para los/as bailarines/ as aymaras el danzar se une a la capacidad de escuchar y expresar emocionalmente el "ritmo musical", lo cual remite a un ámbito de lo sensorio que no se corresponde con la función biológica del oído, sino más bien con el reconocimiento de la propia interioridad o sensibilidad. Así, es muy común observar que las familias incorporen a los/as niños/as desde muy pequeños a las agrupaciones de bailes (cuatro a cinco años), lo que se relaciona con la expresión figurada de que el ritmo musical "viene con uno antes de nacer" o que los wawas o bebés se "gestan, nacen y crecen bailando". La idea de que los/as aymaras poseerían una percepción sonora particular remite a la identificación y definición de la "sangre" como un fluido orgánico y anímico relacionado con el reconocimiento de la propia genealogía y descendencia. De ahí que expresiones como "llevar el ritmo en la sangre", "un 


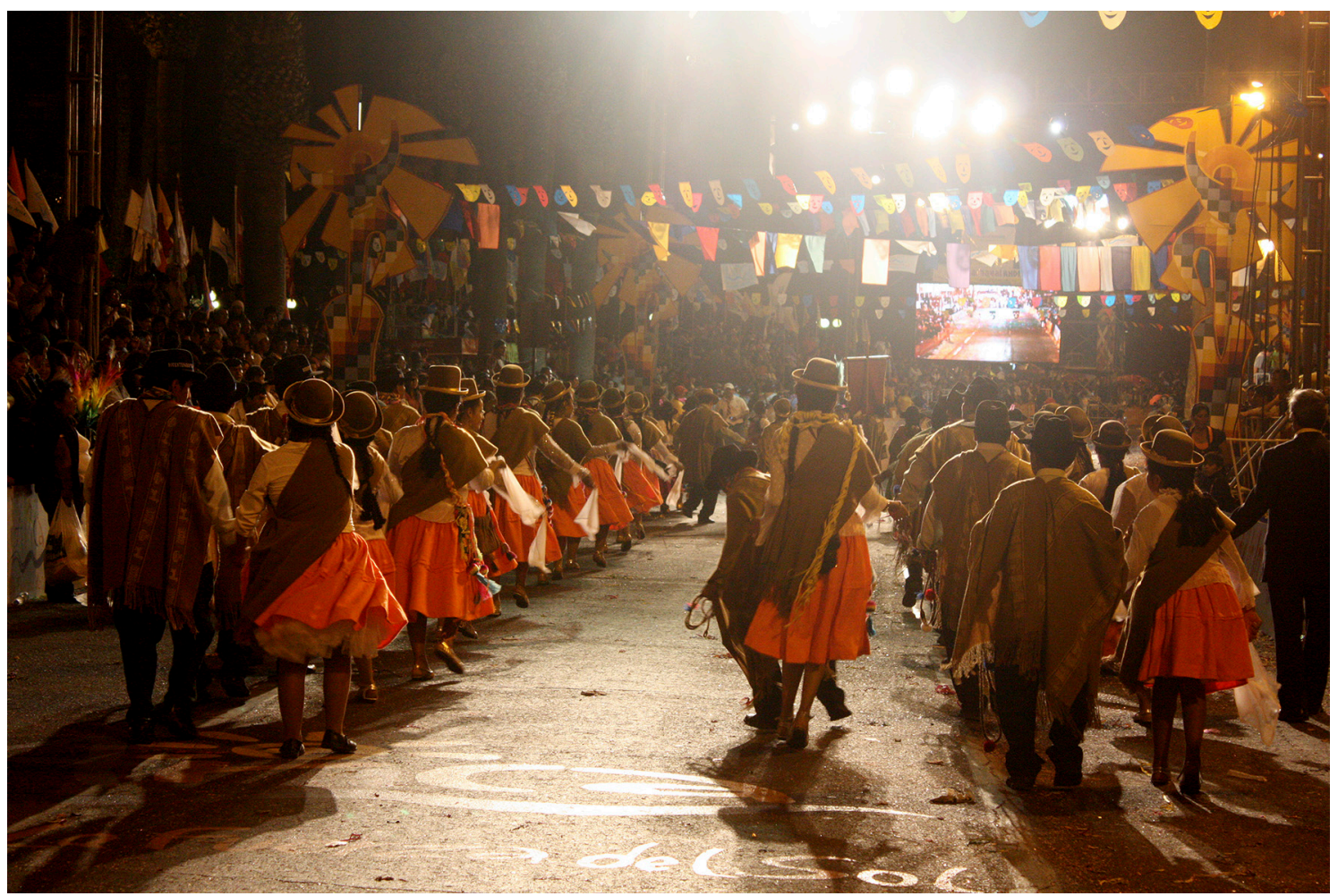

Figura 4. Tarqueada Hijos de Caquena a los pies del Morro de Arica, Carnaval Andino año 2010. (Fotografía: J. P. Donoso). Figure 4. Hijos de Caquena tarqueada at the foot of the Morro de Arica, Andean Carnival 2010. (Photograph: Juan P. Donoso).

sentimiento que corre por las venas" y "la sangre tira", connoten la comprensión de un sí-mismo como una interioridad corporizada.

[y a qué te refieres cuando dices que como que "va en la sangre"] Es que como uno siente la música, uno siente las ganas de bailar, hay gente que baila a [...] qué bonito el baile y baila no más, porque le gustó lo que se ve, por probar. Pero en cambio uno, no, yo no, yo tengo que bailar porque me gusta, yo no puedo escuchar y el cuerpo se mueve solo, eso más que nada, es como uno disfruta con la música, la música le llega a la persona. Yo antes no, yo antes miraba no más y mis primos empezaron a bailar y yo empecé a escuchar, empecé a bailar, le empecé a agarrar gusto y ahora en las fechas yo dependo del carnaval, se me olvida todo así. Hay gente que no le toma valor a los bailes, que bailan solo por eso, por bailar y es un gusto, es un gusto a lo que hace, a las danzas y hay gente que no lo entiende. Pero uno lo baila así porque es lo que uno siente, yo bailo y soy feliz (Entrevista con bailarina y ñusta, Hijos de Parinacota).

Esta naturalización de la escucha musical y la disposición a bailar se relaciona con las prácticas de socialización cotidianas y festivas de las poblaciones aymaras y, por tanto, con el habitus (Bourdieu 1999) que las colectividades reproducen y vivifican en contextos urbanos. La referencia a la "sangre" también se asocia con las definiciones etnofisiológicas del cuerpo en los Andes, las cuales la conciben como un fluido que tiene la capacidad de dar vida y fertilizar, y que se enlaza material y simbólicamente con el linaje (Bastien 1985, Arnold 1994, Platt 2002). Aspectos que, en el caso de los/as bailarines/as, tiene que ver con la conservación del vínculo sensible con los progenitores, abuelos/as, padres, tíos/ as $\mathrm{u}$ otros ascendentes, y a la vez, con una noción de familia que comprende a los parientes genealógicos y a los pueblos de origen. Por otro lado, también refiere a una concepción de familia ritual que se forja en torno a las dinámicas de los grupos de bailes, ya que estos constituyen espacios productivos (ensayos de baile) y reproductivos (conformación de parejas, hijos, etc.) de los bailarines/as y de la colectividad aymara urbana (fig. 4).

Así se entiende, finalmente, que el "corazón" es concebido como un centro corporal que los concentra, que dispersa la "sangre" por las distintas partes del 
cuerpo (Bastien 1985) y otorga carácter y cualidades a las personas en términos de inteligencia, memoria, fortaleza y sensibilidad (Polia 1989, Arnold 1994, La Riva 2005, Gavilán 2005). Subrayo las expresiones: "la sangre tira" o el "llamado de la sangre", pues sugieren que la práctica dancística es una suerte de condición sine qua non de la sensibilidad festiva de los/as bailarines aymaras. En otras palabras, la "sangre" es comprendida y corporizada como una disposición ontológica que hace inevitable el danzar y reproducir el compartir festivo, constituyendo una disposición que permite comprender la adherencia sensible a las tarqueadas como una performance que reúne la memoria temporal, emocional y sonora de los carnavales. De ahí que los/as bailarines/as perciban los efectos sonoros de la música y el ambiente festivo en términos de intensidad o energía, y además, definan y ubiquen ese estado de animación o sensación de estar vivo como "alegría" o "emoción" en el "corazón".

Yo con las tarqueadas las disfruto demasiado, como una cosa que te llama, que te corre por las venas y tú tienes que demostrarlo de alguna manera, entonces me quedé con mi pueblo y qué mejor que representarlo (Entrevista con bailarina y ñusta, Jallalla Parinacota).

\section{CONCLUSIONES}

Sobre la base del calendario agroganadero y la tradición de carnavales que se celebran en los Andes, hemos sugerido que el Carnaval Andino "Inti Chamampi, Con la Fuerza del Sol", que se celebra en Arica, constituye un escenario en el cual los grupos de tarqueadas renuevan sus vínculos sonoros con la memoria y el ambiente festivo, ya sea como performance urbana de los carnavales rurales, o bien como vía de interacción con el espacio urbano. En este sentido, referimos al "llamado de la lluvia" como metáfora de la capacidad de envolver y tocar el paisaje en los términos del diálogo sonoro de la época de lluvias, pues las tarqueadas no solo animan a la audiencia, sino que reviven y reproducen con ella la alegría de los carnavales. Asimismo, sugerimos que el vínculo corporal, estético y emocional con la fiesta aporta a la definición de un sí mismo/a corporizado, cuyos atributos, como la "sangre", permiten comprender la percepción sonora como un dominio de la sensibilidad y la memoria. Es decir, que cuando los bailarines dicen llevar un "corazón contento" o tener "corazón de pueblo" quieren decir que tienen la capacidad de "recordar" el lugar origen y a los abuelos (ancestros), y de expresar y atesorar ese "sentimiento".

\section{NOTAS}

${ }^{1}$ Este trabajo es resultado de los proyectos de investigación "Performance y memoria: la tarqueada en Arica como expresión étnica" (Proyectos Mayores de Investigación Cientifica y Tecnológica Universidad de Tarapacá, año 2018, código 3734-18) y parte de la investigación doctoral denominada "Danzar en el Carnaval Andino 'Inti Chamampi, Con La Fuerza del Sol' de Arica. Cuerpo y performance como representación y experiencia festiva" del Programa de Doctorado en Antropología, Universidad Católica del Norte-Universidad de Tarapacá, Chile.

${ }^{2}$ Los/as investigadores/as regionales del Norte de Chile han denominado como "chilenización" al proceso de control, disciplinamiento y estigmatización de las poblaciones sometidas tras la Guerra del Pacífico (años 1879-1883) (Díaz et al. 2004, Gundermann et al. 2014).

${ }^{3}$ Las ñustas (reinas o princesas) son jóvenes y mujeres de entre 17 a 30 años aproximadamente, que representan públicamente a una agrupación folclórica encabezando pasacalles y desfiles, y participando en las actividades promocionales del Carnaval. Cabe destacar que no solo son elegidas por su antigüedad y habilidades dancísticas, sino que presentan una enorme capacidad para trabajar creativamente por el grupo.

${ }^{4}$ La década de 1960 destaca por una masiva afluencia hacia Arica de un grupo aymara "proveniente del altiplano boliviano y otro del altiplano y precordillera chilena” (Grebe 1986: 205). Se trató de poblaciones que se acoplaron a los recursos de la modernización y gestionaron una residencia costera permanente, ya sea en la ciudad o como trabajadores agrícolas de los valles de Lluta y Azapa. A su vez, mantuvieron un régimen de circulación que los vinculaba social, económica y ritualmente con sus lugares de origen.

${ }^{5}$ La noción de corporización (o embodiment) alude a la agencia social fundada en los aspectos sensoriales y afectivos de la experiencia humana. Se basa en la relación indisoluble del sujeto-mundo como condición de la formación de la conciencia, y alude a la vinculación con otros en la construcción intersubjetiva del sentido común (Csordas 1990).

${ }^{6}$ Los conjuntos (tropas) de flautas de pico se denominan, pinkillus, flautas, lawutas o tarkas (Stobart 2011). La tarka es un aerófono hecho de madera de mara o de tarqu de color blanco que posee un diámetro de 6 a $8 \mathrm{cms}$., tendiendo a ser hexagonal en sus extremos; posee seis orificios y puede utilizar una escala musical pentatónica o bien de siete notas (López 2007). Generalmente, las tarkas se presentan "como una familia conformada por cuatro tropas u orquestas con 
sus respectivos tamaños: taika, malta, tiple o chuli" (Borras 2011: 59). Entre los Carangas, López (2007) identifica las tres medidas y las distingue de la tarqa potosina, la tarqa salinas y la tarqa kurawara (López 2007).

${ }^{7}$ De acuerdo con Stobart (2011: 20), el sonido de las tarkas se asocia con una manera de tocar denominada "tara", la que produce "un sonido rico y denso, y una calidad de tartamudeo (tartamuliata). Este sonido vibrador es causado por fuertes batidos diferenciales que son procurados y apreciados por un ideal estético".

${ }^{8}$ El Convite es un ensayo general del Carnaval que las agrupaciones folclóricas realizan en el circuito del desfile. Tiene el objetivo de marcar los tiempos y posiciones de los participantes, a la vez que anunciar y promocionar la fiesta.

${ }^{9}$ Excepciones, identificadas a la fecha, son la Tarqueada de Molinos, la que junto con los ensayos desarrollan una "escuela de tarka" y la Comparsa de Socoroma Phusiri Marka, quienes poseen un desarrollo independiente como grupo de proyección musical andina.

${ }^{10} \mathrm{He}$ publicado los registros visuales, sonoros y audiovisuales de algunas tarqueadas investigadas en la página web. www.tarqueadas.cl, proyecto financiado por el Fondo de la Música del Ministerio de las Culturas, las Artes y el Patrimonio, año 2018.

\section{REFERENCIAS}

ARnold, D. 1994. Hacer al hombre a imagen de ella: aspectos de género en los textiles de Qaqachaka. Chungara 26 (1): 79-115.

BAjtin, M. 2003. La cultura popular en la Edad Media y en el Renacimiento. El contexto de François Rabelais. Madrid: Alianza.

Bastien, J. 1985. Qollahuaya-Andean body concepts: a topographical-hydraulic model of physiology. American Anthropologist 87 (3): 595-611.

BigenHO, M. 1999. Sensing locality in Yura: ritual of carnaval and of the bolivian state. American Ethnologist 26 (4): 957-980.

Borie, C., Fortunato, A., Mora, G. \& Solar, J. 2008. Azapa. El Ño carnavalón. Un carnaval en San Miguel de Azapa. Santiago: Consejo Nacional de la Cultura y las Artes Gobierno de Chile-Azapa Expresiones.

Borras, G. 2011. Organología de la tarka en la zona circumlacustre del Titicaca. In Diablos tentadores y pinkillos embriagadores... en la fiesta de Anata/Phujllay. Estudios de antropología musical del carnaval en los Andes de Bolivia. Tomo 1, G. Arnaud, Ed., pp. 41-67. La Paz: Plural.

Bourdieu, P. 1999. El conocimiento por cuerpos. In Meditaciones pascalianas, pp. 169-214. Barcelona: Anagrama.

Cánepa, G. 2008. Identidad y memoria. In Fiesta en los Andes. Ritos, música y danzas del Perú, R. Romero, Comp., pp. 42-71. Lima: Fondo Editorial Pontificia Universidad Católica del Perú.
CARo Baroja, J. 1984. El carnaval (análisis histórico-cultural). Madrid: Taurus.

Chamorro, A. 2013. Carnaval Andino en la ciudad de Arica. Estudios Atacameños 45: 41-54.

Chamorro, A. 2017. Imagen y experiencia: el Carnaval de Arica como autorrepresentación festiva. Chungara 49 (1): 121-132.

Classen, C. 1990. Sweet colors, fragrant songs: sensory models of the Andes and the Amazon. American Ethnologist 17 (4): 722-735.

Classen, C. 1993. Inca cosmology and the human body. Salt Lake City: University of Utah Press.

Classen, C. 1997. Fundamentos de una antropología de los sentidos. International Social Science Journal 49 (3): 401-412.

Csordas, T. 1990. Embodiment as paradigm anthropology. Ethos 18 (1): 5-47.

CopA, L. 2010. La tarqueada tradicional aimara: Curahuara de Carangas y San Pedro de Curahuara. In Diablos tentadores y pinkillus embriagadores... en la fiesta de Anata/Phujllay. Estudios de antropología musical del carnaval en los Andes de Bolivia. Tomo 2, G. Arnaud, Ed., pp. 25-98. La Paz: Plural.

Denzin, N. 2001. The reflexive interview and a performative social science. Qualitative Research 1 (1): 23-46.

Díaz, A. \& Mondaca, C. 2000. El sonido de las tarkas entre músicos aymaras chilenos y bolivianos. Diálogo Andino 19: 63-70.

Díaz, A., Ruz, R. \& Mondaca, C. 2004. La administración chilena entre los aymaras: resistencia y conflicto en los Andes de Arica (1901-1926). Anthropologica 22 (22): 216-231.

Díaz, A., Martínez, P. \& Ponce, C. 2014. Cofradías de Arica y Tarapacá en los siglos XVIII y XIX. Indígenas andinos, sistema de cargos religiosos y festividades. Revista de Indias LXXIV (260): 101-128.

Fernández, G. 2008. Kharisiris en acción. Cuerpo, persona y modelos médicos en el Altiplano de Bolivia. La Paz: Abya Yala.

Flores, J. A. 2001. Un continente de Carnaval: etnografía crítica de carnavales americanos. Seminario Etnografías e interpretación de carnavales americanos, 26 de febrero al 2 de marzo. Madrid: Aula de Estudios Americanistas del Museo de América.

GAignebet, C. 1984. El carnaval. Ensayos de mitología popular. Barcelona: Alta Fulla.

Gavilán, V. 2005. Representaciones del cuerpo e identidad de género y étnica en la población indígena del norte de Chile. Estudios Atacameños 30: 135-148.

Gavilán, V. \& Carrasco, A. 2009. Festividades andinas y religiosidad en el norte chileno. Chungara 41 (1): 101-112.

GÉrard, A. 2011. Anata/Phujllay, ¿el gran juego? Una aproximación semántica. In Diablos tentadores y pinkillos embriagadores... en la fiesta de Anata/Phujllay. Estudios de antropología musical del carnaval en los Andes de Bolivia. Tomo 2, G. Arnaud, Ed., pp. 313-340. La Paz: Plural.

GISBERT, T. 1999. El control de lo imaginario: teatralización de la fiesta. In El paraíso de los pájaros parlantes. La imagen 
del otro en la cultura andina, T. Gisbert, Ed., pp. 237-256. La Paz: Plural-Universidad Nuestra Señora de La Paz.

GonzÁlez, H. 1995. La inserción económica de los migrantes aymara en la ciudad. El trabajo como empresa familiar y la reproducción cultural. In Actas del Segundo Congreso Chileno de Antropología. Tomo I, pp. 315-324. Valdivia: Colegio de Antropólogos de Chile.

GonzÁlez, H. 1997. Apuntes sobre el tema de la identidad cultural en la Región de Tarapacá. Estudios Atacameños 13: 9-26.

Grebe, M. E. 1986. Migración, identidad y cultura aymará: puntos de vista del actor. Chungara 16-17: 205-223.

Gundermann, H., González, H. \& Durston, J. 2014. Relaciones sociales y etnicidad en el espacio aymara chileno. Chungara 46 (3): 397-421.

HARris, O. 1983. Los muertos y los diablos entre los laymi de Bolivia. Chungara 11: 135-152.

INSTITUTO DE INVESTIGACIÓN CULTURAL PARA EDUCACIÓN POPULAR. 1973. El carnaval en las comunidades aymaras del departamento de Oruro. IICEP 7 (10): 1-9.

LA Riva, P. 2005. Las representaciones del animu en los Andes del sur peruano. Revista Andina 41: 63-89.

López, U. 2007. Anata andino. Máscaras y danzas de los ayllus de Oruro. Oruro: CEPA.

Martínez, G. 1996. Saxra (Diablo)/Pachamama: música, tejido, calendario e identidad entre los jalq’a. In Cosmología $y$ música en los Andes, M. P. Baumann, Ed., pp. 283-310. Madrid: Iberoamericana.

Martínez, R. 1996. El sajra en la música de los jalq’a. In Cosmología y música en los Andes, M. P. Baumann, Ed., pp. 311-322. Madrid: Iberoamericana.

Martínez, R. 2014. Músicas, movimientos, colores en la fiesta andina. Ejemplos bolivianos. Anthropologica 32 (33): 87-110.

Mendoza, Z. 2010. La fuerza de los caminos sonoros: caminata y música en Qoyllurit'i. Anthropologica 28 (28): 15-38.

Merleau-Ponty, M. 2008. El mundo de la percepción. Siete conferencias. Buenos Aires: Fondo de Cultura Económica.

Platt, T. 2002. El feto agresivo. Parto, formación de la persona y mito-historia en los Andes. Estudios Atacameños 22: 127-155.

Polia, M. 1989. "Contagio" y "pérdida de la sombra" en la teoría y práctica del curanderismo andino del Perú septentrional: Provincias de Ayabaca y Huancabamba. Anthropologica 7 (7): 195-231.

Prat I CARós, J. 1993. El carnaval y sus rituales: algunas lecturas antropológicas. Temas de Antropología Aragonesa 4: 278-296.

ReNGIfo, G. 2006. El calendario agrofestivo -wata muyuy- en comunidades andinas. Apuntes. In Calendario Agrofestivo en Comunidades y Escuela, Proyecto Andino de Tecnologías Campesinas (PRATEC), Ed., pp. 41-49. Lima: Bellido.

Romero, J. 2012. Colonialidad y dinámica festiva. Legitimación de la modernidad/colonialidad en el carnaval de Oruro. T'inkazos 31: 137-156.
Rossells, B., Peres, J., Aparicio, K., Borrega, Y. \& Ricaldi, V. 2009. Carnaval paceño y jisk'a anata. Instituto de Estudios Bolivianos. Tomo I. La Paz: IEB.

SigL, E. 2009. Donde papas y diablos bailan. Danza, producción agrícola y religión en el altiplano boliviano. Maguaré 23: 303-341.

SIGL, E. 2011. Cuando mujeres se visten de flores y chacras bailan. Danza, fertilidad y espiritualidad en el altiplano boliviano. Anthropos 106 (2): 475-492.

Sigl, E. 2012. No se baila así nomás... Poder, política, género, etnicidad, clase, religión y biodiversidad en las danzas del altiplano boliviano. Tomo I. La Paz: Autoedición.

Stobart, H. 2006. The animated soundscape and the mountain's bones. In Kay Pacha. Cultivating earth and water in the Andes, P. Dransart, Ed., pp. 99-106. Oxford: British Archaeological Reports.

Stobart, H. 2011. Tara y q'iwa. Mundo de sonidos y significados. In Diablos tentadores y pinkillos embriagadores... en la fiesta de Anata/Phujllay. Estudios de antropología musical del carnaval en los Andes de Bolivia. Tomo 1, G. Arnaud, Ed., pp. 25-40. La Paz: Plural.

Surrallés, A. 2009. De la intensidad o los derechos del cuerpo. La afectividad como objeto y como método. Runa xxx (1): 29-44.

TAYLOR, D. 2015. El archivo y el repertorio. La memoria cultural performática en las Américas. Santiago: Ediciones Alberto Hurtado.

Vokral, E. 1996. La instauración del orden: las coplas de carnaval y su ambiente social (provincia de Chimborazo, Ecuador). In Cosmología y música en los Andes, M. P. Baumann, Ed., pp. 394-416. Madrid: Iberoamericana.

ZAPATA, C. 2001. Las voces del desierto: identidad aymara en el norte de Chile. Santiago: Ril. 